\title{
Deriving Changjiang coastal zone wind from C-band SAR and its application to salinity simulation*
}

\author{
WANG Lihua (王利花), ZHOU Yunxuan (周云轩) ${ }^{* *}$, ZHU Jianrong (朱建荣), \\ SHEN Fang (沈芳), TIAN Bo (田波) \\ State Key Laboratory of Estuarine and Coastal Research, East China Normal University, Shanghai 200062, China \\ Received Sep. 18, 2013; accepted in principle Oct. 20, 2013; accepted for publication Oct. 31, 2013 \\ (C) Chinese Society for Oceanology and Limnology, Science Press, and Springer-Verlag Berlin Heidelberg 2014
}

\begin{abstract}
Wind plays an important role in hydrodynamic processes such as the expansion of Changiang (Yangtze) River Diluted Water (CDW), and shelf circulation in the Changjiang estuary. Thus, it is essential to include wind in the numerical simulation of these phenomena. Synthetic aperture radar (SAR) with high resolution and wide spatial coverage is valuable for measuring spatially inhomogeneous ocean surface wind fields. We have collected 87 ERS-2 SAR images with wind-induced streaks that cover the Changjiang coastal area, to verify and improve the validity of wind direction retrieval using the $2 \mathrm{D}$ fast Fourier transform method. We then used these wind directions as inputs to derive SAR wind speeds using the C-band model. To demonstrate the applicability of the algorithms, we validated the SAR-retrieved wind fields using QuikSCAT measurements and the atmospheric Weather Research Forecasting model. In general, we found good agreement between the datasets, indicating the reliability and applicability of SARretrieved algorithms under different atmospheric conditions. We investigated the main error sources of this process, and conducted sensitivity analyses to estimate the wind speed errors caused by the effect of speckle, uncertainties in wind direction, and inaccuracies in the normalized radar cross section. Finally, we used the SAR-retrieved wind fields to simulate the salinity distribution off the Changjiang estuary. The findings of this study will be valuable for wind resource assessment and the development of future numerical ocean models based on SAR images.
\end{abstract}

Keyword: synthetic aperture radar (SAR); Changjiang estuary; fast Fourier transformation (FFT); C-band model (CMOD4); weather research forecasting model (WRF)

\section{INTRODUCTION}

Sea surface wind, which is directly related to almost all ocean water movement, is a crucial parameter in studies of hydrodynamic and ecological processes (Blanton et al., 1995; Genovese and Witman, 2004). Such studies include the expansion of Changjiang (Yangtze) River Diluted Water (CDW) and shelf circulation in the Changjiang estuary. CDW extends to the northeast in the form of a plume during the summer, but in winter, it clings to the Chinese coast in a narrow band on the southwest. A southerly wind prevails in the estuary in summer, while a northerly wind prevails in winter. Wind-driven Ekman transport leads to remarkable seasonal variations of CDW distribution (Zhu et al., 1997; Chang and Isobe, 2003). High-resolution ocean surface wind measurements are essential for accurate numerical simulation of these phenomena. However, there is a shortage of observed wind data in the East China Sea (ECS). Currently, prevailing ocean surface wind field estimation, based on meteorological models and satellite-borne scatterometer (SCAT) measurements, only has a resolution of around $25 \mathrm{~km}$ (Horstmann et al., 2000a). This resolution is not sufficient for the numerical model. Synthetic aperture radar (SAR) covers large areas at a high-resolution and for all weather conditions; therefore, it is valuable when deriving ocean surface wind fields. Since the launch

\footnotetext{
* Supported by the National Basic Research Program of China (973 Program) (No. 2010CB951204) and the State Key Laboratory of Estuarine and Coastal Research grant (No. SKLEC-2012KYYW02)

** Corresponding author: zhouyx@sklec.ecnu.edu.cn
} 
of the European remote sensing satellite ERS-1 in 1991 (Attema, 1991), SAR images have provided a continuous record of ocean surface observations. These images have recently been used to measure various global features such as ocean surface winds, waves, and currents (Johannessen, 2000; Fichaux and Ranchin, 2002; Christiansen et al., 2006). Despite variations in wind speed and direction, SAR images can reveal high-resolution patterns. Therefore, it may soon be possible to operationally measure ocean surface wind from space, especially in coastal areas.

Backscattered power from the ocean surface at radar frequencies is a function of wind speed, the relative angle between the radar look and wind directions, and the incidence angle. For small incidence angles $\left(\leq 10^{\circ}\right)$, we can use the normalized radar cross section (NRCS) $\sigma^{0}$ to compute wind speed, but it provides no wind direction information. For incidence angles of $10^{\circ}-15^{\circ}, \sigma^{0}$ is insensitive to both wind speed and direction (Freilich and Chelton, 1986). For moderate incidence angles $\left(15^{\circ}-70^{\circ}\right)$, the radiation backscattered from the ocean surface is dominated by Bragg scattering from cm-scale surface roughness, which is resonant with incident electromagnetic radiation (Wright, 1966; Valenzuela, 1978; Freilich and Chelton, 1986). Additionally, Raleigh scattering and specular (mirror-like) reflections may contribute to the backscatter. Wright (1966) gave a detailed description of the scattering mechanism. Many studies have shown that the spectral density of cm-scale ocean surface waves is strongly dependent on the local surface wind stress. Consequently, a number of researchers have focused on using SAR to measure wind fields, developing algorithms for wind vector measurement (Lehner et al., 2000; Zou et al., 2007). Two primary methods have been developed to retrieve the orientation of linear features that are aligned with the wind direction in SAR images. One in the spectral domain (Gerling, 1986; Vachon and Dobson, 1996; Wackerman et al., 1996; Fetterer et al., 1998; Kerbaol et al., 1998; Korsbakken et al., 1998; Lehner et al., 2000), and one in the spatial domain (Fichaux and Ranchin, 2002; Horstmann et al., 2002; Koch, 2004; Horstmann and Koch, 2005). Wind speed can be calculated from accurately calibrated SAR images using a semiempirical geophysical model function (GMF) for VV polarization (Korsbakken et al., 1998; Horstmann and Koch, 2005; Christiansen et al., 2006). A hybrid model consisting of a VV-polarized GMF and a polarization ratio model is typically used for wind speed retrieval from C-band (5.34 GHz) SAR images acquired at $\mathrm{HH}$ polarization (Horstmann et al., 2000a, b; Kim and Moon, 2002; Horstmann et al., 2004; Horstmann and Koch, 2005).

SAR-retrieved wind speeds using wind direction observations from meteorological masts are of excellent quality (Hasager et al., 2005). However, wind directions from in-situ measurements are generally not available. Therefore, it would be advantageous to derive wind direction directly from SAR images. Wind direction can be extracted using a 2D fast Fourier transformation (FFT) in the spectral domain, but it is a controversial method because of the optimal selection of scale, relatively low spatial resolution, and $180^{\circ}$ directional ambiguity. In this study, we have used 87 ERS-2 SAR images (Haarpaintner, 1999) with visible wind-induced streaks to derive wind vectors in the Changjiang coastal area, to demonstrate and improve the validity of the 2D FFT method. Preliminary comparisons of wind speed retrieval have indicated that the GMF CMOD4 (C-band Model) yields accurate estimations under low and moderate wind conditions. However, fewer than 2000 data pairs were taken into account (Horstmann et al., 2005; Lin et al., 2008). In this paper, we have examined the applicability of the 2D FFT algorithm and the CMOD4 model, and improved their performance under different atmospheric conditions. We systematically compared SARretrieved wind fields with measurements from the NASA SeaWinds SCAT on QuikSCAT, and results from the mesoscale atmospheric Weather Research Forecasting model (WRF). Our analysis is more comprehensive than previous wind field validation studies, because we have used a sufficient number of SAR scenes to provide relatively robust statistics. For the study site in the Changjiang coastal area, SAR and in-situ observations are probably affected by atmospheric stability (Stull, 1988) and internal boundary layers from land (Garratt, 1990). We briefly address the effects of these factors on wind field retrieval, and quantitatively discuss the major sources of wind speed error with respect to ERS-2 SAR data. Furthermore, we focus on the application of SARretrieved wind fields to numerical simulations of the ocean.

\section{METHOD}

\subsection{Datasets}

The study area is located between $29^{\circ} 50^{\prime}-32^{\circ} 40^{\prime} \mathrm{N}$ 
Table 1 ERS-2 data acquisition parameters

\begin{tabular}{|c|c|c|c|c|c|c|}
\hline Product & Polarization mode & Year of data & Month of data & Data time (UTC) & Number of different days & Total \\
\hline \multirow{5}{*}{ ERS-2 SAR PRI } & \multirow{5}{*}{ VV } & 2006 & Jan.-Jul. & $02: 24: 53-02: 31: 06$ & 12 & 26 \\
\hline & & 2007 & Jan.-Dec. & $02: 22: 08-02: 28: 25$ & 15 & 39 \\
\hline & & 2008 & May, Aug., Nov., Dec. & $02: 23: 17-02: 32: 26$ & 5 & 9 \\
\hline & & 2009 & Jan., Mar., May, Oct., Dec. & $02: 24: 06-02: 32: 52$ & 7 & 13 \\
\hline & & & & & 39 & 87 \\
\hline
\end{tabular}

and $120^{\circ} 30^{\prime}-124^{\circ} 30^{\prime} \mathrm{E}$ in the ECS, and covers the Changjiang coastal area, the maximum turbidity zone, and the area off the Changjiang estuary (Fig.1). The ERS-2 SAR images were obtained from the C-band $(5.3 \mathrm{GHz})$ using $\mathrm{VV}$ polarization at moderate incidence angles of $19.5^{\circ}-26.5^{\circ}$. They were collected from January 2006 to December 2009, when ERS-2 passed over the study area at approximately 02:30 UTC. In this study, we also collected observational data from the Dajishan and Tanhu meteorological stations. We selected 87 ERS-2 SAR images with visible wind-induced streaks (Table 1). The images cover 39 different days and present varied sea surface conditions, including stable, near-neutral, and unstable. The wind in each image varies. We calibrated the ERS-2 SAR images using the complete calibration formula described by Laur et al. (2004). In addition, we obtained an ASAR image from the European remote sensing satellite ENVISAT (Zink et al., 2002), which operated at the C-band with $\mathrm{HH}$ polarization over the ECS at 02:01 UTC on July 6 2011. The image, obtained in the global monitoring mode, has a swath width of up to $\sim 400 \mathrm{~km}$ and a spatial resolution of $\sim 500 \mathrm{~m}$. Wind fields retrieved from this image were then used in numerical ocean simulations.

The SeaWinds scatterometer on QuikSCAT is a conical scanning pencil-beam radar, which is capable of dual-beam and dual-polarization, and operates in the Ku-band to retrieve all-weather ocean surface wind vectors. The wind vector dataset has been processed by the QuikSCAT Project using the QSCAT-1 GMF, and has been updated regularly since July 1999. We downloaded all of the QuikSCAT Level-2B wind vectors data at $12.5 \mathrm{~km}$ resolution for the time corresponding to the SAR images.

WRF (Done et al., 2004) was designed for both operational forecasting and atmospheric research. It is a next-generation, limited-area, nonhydrostatic, and regional meteorological model. In this study, we have used the triple-nested WRF model with initial lateral boundary values derived from the National Center of Environment Prediction (NCEP) reanalysis

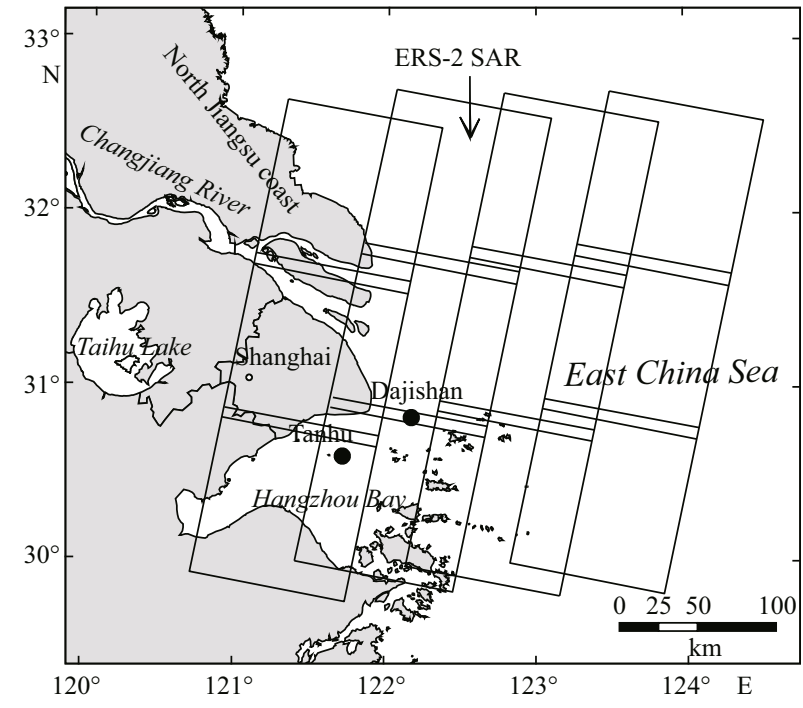

Fig.1 Location of Changjiang coastal area, ERS-2 SAR images (rectangles), and meteorological stations (dots)

data on a $1^{\circ} \times 1^{\circ}$ grid at $3 \mathrm{~h}$ intervals. The WRF model results were available at $1 \mathrm{~h}$ intervals and $9 \mathrm{~km}$ resolution. We collected WRF results with the same spatial coverage as the SAR images, using time offsets to reflect the SAR observation times.

\subsection{Wind direction retrieval}

It is important to appropriately select the scale when using the 2D FFT to extract wind direction, because the accuracy is strongly dependent on the orientation of the wind-induced streaks. Dankert et al. (2003) have shown that wind-induced streaks in highresolution real aperture radar (RAR) images at scales of 50-1 $500 \mathrm{~m}$ are very well aligned with the mean surface wind direction. Horstmann and Koch (2005) showed that the energy densities for wavelengths of wind-induced streaks at scales of 500-1 $800 \mathrm{~m}$ are associated with the average wind direction. Their results have encouraged us to focus on the smallest scales possible using space-borne SAR images. Under ideal circumstances, when SAR images present the linear features that are associated with sea surface 


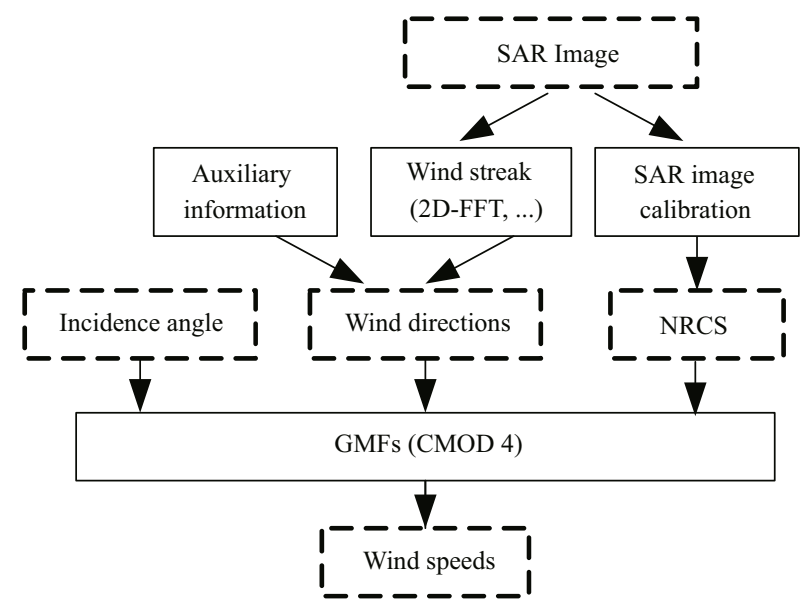

Fig.2 Schematic description of wind retrieval from SAR images

wind fields, they are likely to show high-resolution changes in wind direction. We obtain high-resolution wind directions using the following process. First, we mask all pixels representing land, surface slicks, and artifacts in SAR images not affected by the local ocean surface wind. Next, the SAR images are divided into sub-images, because the wind-induced streak features typically exhibit km-scale spacing. The subimages quantitatively express the wind direction resolution (which is set to $6.4 \mathrm{~km} \times 6.4 \mathrm{~km}$ ). Third, we apply the 2D FFT to SAR images. Because there are high-frequency noises in the Fourier spectra, we use filters (Argenti and Alparone, 2002) to eliminate SAR speckle. Then, we use least-squares estimation to calculate the regression, and consider the energy densities for wavelengths of 500-2 $000 \mathrm{~m}$. We use thresholds to exclude small ocean surface waves $(<500 \mathrm{~m})$ and larger scale features $(>2000 \mathrm{~m})$. Finally, we obtain the regression line, which is perpendicular to the orientation of the wind streaks with a $180^{\circ}$ directional ambiguity. There is no $180^{\circ}$ wind directional ambiguity if wind shadowing is present in the SAR images, which is often the case in the lee of coastlines. If SAR images do not contain such features, auxiliary information is used, e.g., atmospheric models, in-situ measurements, or weather charts.

\subsection{Wind speed retrieval}

For instruments operating in the C-band with VV polarization, the relationship between wind speed, wind direction, and NRCS (the GMF) is generally expressed using

$$
\sigma^{0}=A\left(u_{10}, \theta\right)\left[1+b\left(u_{10}, \theta\right) \cos \phi+c\left(u_{10}, \theta\right) \cos \varphi\right]^{B},
$$

where $\sigma^{0}$ is the NRCS in linear units, $\varphi$ is the difference between the wind and antenna look directions, $u_{10}$ is wind speed, $\theta$ is the nadir incident angle, and $A, b, c$, and $B$ are model parameters that depend on the radar frequency, polarization, $u_{10}$, and $\theta$.

We have used the GMF CMOD4 (Stoffelen and Anderson, 1997) to calculate the wind speed. This GMF was originally developed to derive wind speed from ERS SCAT. Because SCAT and SAR operate at the same frequency and polarization, we can apply CMOD4 (similar in form to Eq.1) to SAR. The GMF CMOD4 used here was developed and validated using a large amount of measured data. For instruments operating in the C-band with $\mathrm{HH}$ polarization, we have used a hybrid model consisting of CMOD4 and the polarization ratio according to Kirchhoff scattering (Elfouhaily et al., 1999; Thompson et al., 1999). We extracted the wind directions (necessary input parameters to CMOD4) from wind-induced streaks using the 2D FFT method, as mentioned in Subsection 2.2. A flowchart of the wind field retrieval scheme is shown in Fig.2.

\subsection{Comparison and validation}

We validated the SAR-retrieved wind vectors using QuikSCAT data and WRF results. We have compared the results on a case-by-case basis, using linear regression analysis to demonstrate the capability of SAR and investigate wind vector retrieval using the 2D FFT and CMOD4.

When comparing SAR-retrieved wind vectors with QuikSCAT wind products, we used SAR wind vectors from the area corresponding to the QuikSCAT grid. This resulted in a grid-cell size of approximately $12.5 \mathrm{~km} \times 12.5 \mathrm{~km}$. When comparing the SARretrieved wind fields and the WRF model results, we averaged the SAR images so that they agreed with the grid-cell size of the WRF model output, which was approximately $9 \mathrm{~km} \times 9 \mathrm{~km}$. To select the effective dataset, we collected all QuikSCAT and WRF results that had the same spatial coverage as the SAR images and were within a $\pm 30 \mathrm{~min}$ offset of the SAR acquisition time. We also excluded SAR data that was contaminated by rain or oil spills. When SAR NRCS is greater than $-1 \mathrm{~dB}$, we observed that more than $1 \mathrm{~dB}$ of power was lost. Although the calibration accounted for this power loss, NRCS values greater than $-1 \mathrm{~dB}$ still exist and have a strong effect on wind speed measurements. Consequently, we excluded NRCS values larger than $-1 \mathrm{~dB}$ from our comparisons. The final comparison dataset consisted of 4120 SAR- 

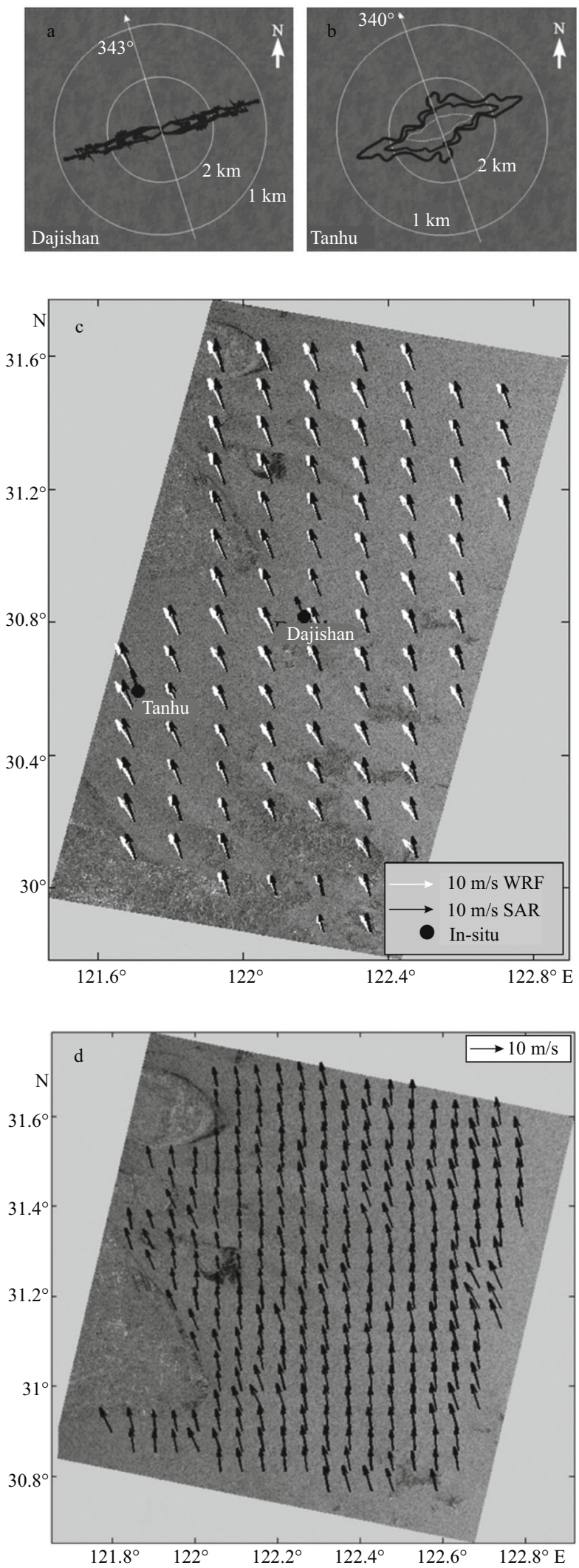

Fig.3 Low-wavenumber estimation of wind directions at (a) Dajishan and (b) Tanhu; mosaic of (c) two ERS-2 SAR images obtained over Changjiang coastal area on May 4, 2006, and (d) high-resolution (5 km) wind field retrieval from a ERS-2 SAR image
QuikSCAT pairs. We also compared SAR-retrieved wind fields and WRF results using a larger dataset, to examine the applicability of the SAR-retrieved algorithm under different atmospheric conditions. This dataset is composed of all the ERS-2 SAR scenes mentioned above, and contains 9505 SAR-WRF pairs.

\section{RESULT}

\subsection{Examples of SAR-retrieved wind fields}

Examples of estimated wind directions in the spectral domain at the Dajishan and Tanhu meteorological stations are shown in Fig.3a and b. We have removed the $180^{\circ}$ directional ambiguities by adjusting for the wind shadowing visible in the SAR image.

Figure $3 \mathrm{c}$ is a mosaic of two ERS-2 SAR images obtained over the Changjiang coastal area on May 4, 2006. The data were acquired at 02:27 UTC and 02:28 UTC. The wind vectors retrieved from the SAR images (black arrows) and computed from the WRF model (white arrows), and observations from the meteorological stations are superimposed on the image. The WRF model results are available at $1 \mathrm{~h}$ intervals, so we have interpolated the wind vectors to the precise SAR acquisition time using the natural neighbor method. According to Fig.3c, the SARretrieved wind vectors are in good agreement with the WRF model results in both direction and magnitude.

Figure $3 \mathrm{~d}$ shows an ERS-2 SAR image of the Changjiang coastal area acquired on May 4, 2006, at 02:27 UTC. Superimposed on the image are wind vectors with a resolution of $5 \mathrm{~km}$, retrieved using the 2D FFT and CMOD4. We have removed the wind direction ambiguities by adjusting for wind shadowing, which is especially visible on the east coast of Changjiang. The wind direction in Fig.3d agrees with the WRF model results on the coarse grid (top of Fig.3c). Nevertheless, near the east coast of Changjiang, there is a slight change in wind direction toward the west that is not effectively resolved in the WRF model. The SAR-derived wind speed is very similar to that derived using the WRF model (top of Fig.3c).

Table 2 shows that the wind direction estimates from the SAR image and the WRF model are in good agreement with the observed measurements. There is only a slight difference (within $5^{\circ}$ ) between the SARretrieved wind direction and the observed data. For wind speed, results derived from SAR data and the 
Table 2 Observed wind vectors and estimated wind field results

\begin{tabular}{|c|c|c|c|c|c|c|}
\hline \multirow{2}{*}{ Test site } & \multicolumn{3}{|c|}{ Wind direction $\left({ }^{\circ}\right)$} & \multicolumn{3}{|c|}{ Wind speed $(\mathrm{m} / \mathrm{s})$} \\
\hline & Observed data & SAR-retrieved & WRF model & Observed data & SAR-retrieved & WRF model \\
\hline Dajishan & 340 & 343.0 & 335.0 & 9.8 & 8.6 & 8.3 \\
\hline Tanhu & 345 & 340.0 & 329.6 & 10.3 & 9.9 & 9.5 \\
\hline
\end{tabular}
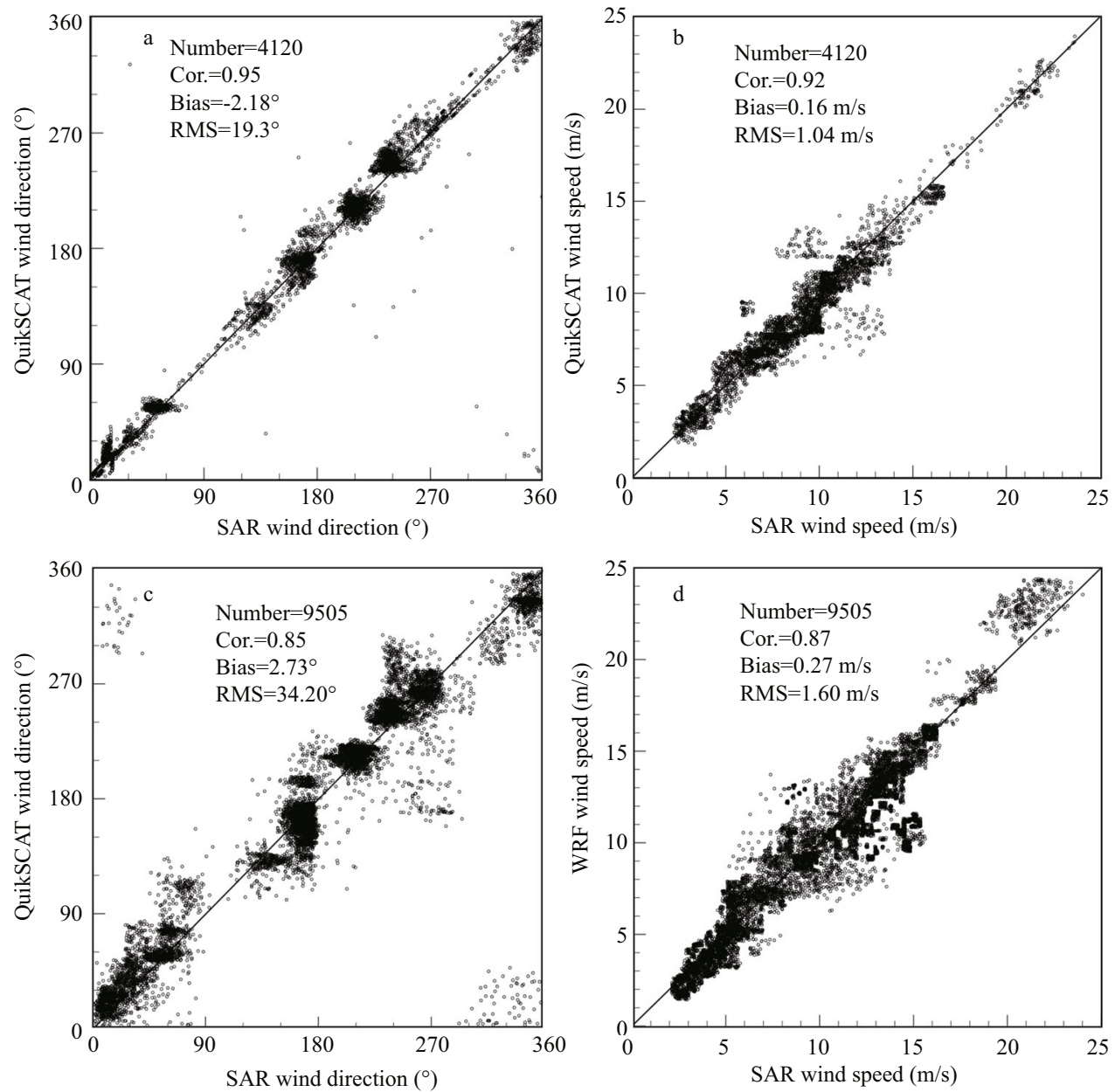

Fig.4 Scatterplots of wind field results from QuikSCAT versus SAR images, and WRF model versus SAR images

WRF model are close to the observed values, although results from the SAR data are slightly better than the WRF model outputs.

\subsection{Comparison of SAR wind retrieval methods}

Figure $4 \mathrm{a}$ and $\mathrm{b}$ compare QuikSCAT products with the SAR results. The results of a linear regression analysis between SAR wind direction and QuikSCAT wind direction indicate a bias of $-2.18^{\circ}$, a root-meansquare error (RMS) of $19.3^{\circ}$, and a correlation coefficient $\left(R^{2}\right)$ of 0.95 . We can calculate SARretrieved wind speed by using wind direction deduced from the 2D FFT of SAR wind-streaks as input to CMOD4. Linear regression analysis between the SAR-retrieved wind speed and QuikSCAT wind speed resulted in a bias of $0.16 \mathrm{~m} / \mathrm{s}$, RMS of $1.04 \mathrm{~m} / \mathrm{s}$, and $R^{2}$ of 0.92 . These promising results suggest that QuikSCAT and SAR are both effective data sources for calculating ocean surface wind fields. Although QuikSCAT can only produce wind vectors at a resolution up to $12.5 \mathrm{~km}$, it is better for open ocean measurements. In coastal regions, where wind fields can vary dramatically over a few kilometers, SAR images are able to offer sub-km resolution. Therefore, 
we can obtain an improved global wind product by combining QuikSCAT wind products in open ocean areas with high-resolution SAR-retrieved wind fields in coastal areas.

WRF measurements are compared to SARretrieved results in Fig. $4 \mathrm{c}$ and d. A linear regression analysis of wind direction resulted in a bias of $2.73^{\circ}$, RMS of $34.20^{\circ}$, and $R^{2}$ of 0.82 . For wind speed, the bias was $0.27 \mathrm{~m} / \mathrm{s}$, RMS $1.60 \mathrm{~m} / \mathrm{s}$, and $R^{2} 0.87$, indicating that the SAR-retrieved wind fields do not correspond as closely to WRF data as QuikSCAT. Moreover, when used with SAR images, CMOD4 underestimates high wind speeds $(>20 \mathrm{~m} / \mathrm{s})$ and overestimates low wind speeds ( $<3 \mathrm{~m} / \mathrm{s})$ (Fig.4d).

\section{DISCUSSION}

\subsection{Advantages and disadvantages of methods}

The SAR-retrieved wind directions agree well with observations from the Dajishan and Tanhu meteorological stations (Table 2 and Fig.3c). The discrepancies are within 5 degrees, which is far better than expected. The results may be explained as follows. The 2D FFT method for estimating wind direction from wave domain information is more stable than searching for a maximum of the FFT or the gradient method. In addition, SAR wind direction retrieval uses the orientation of $\mathrm{km}$-scale surface features such as wind-driven Langmuir circulations. It is difficult to derive precise wind direction when wind speed is very low or atmospheric conditions are stable. The wind speed of the example image is $\sim 8-$ $10 \mathrm{~m} / \mathrm{s}$. Therefore, we deduce that the 2D FFT method produces accurate wind direction estimations when the wind speed is greater than approximately $7-8 \mathrm{~m} / \mathrm{s}$. Large discrepancies between SAR-retrieved and insitu wind direction observations are probably caused by non-wind-driven features that are at the same scale as wind-driven features, e.g., ocean waves.

For the east coast of Changjiang estuary, the SAR image shows much finer detail in wind structure and higher variability in wind direction than the WRF wind results (Fig.3d). This is due to the high-resolution SAR snapshot of a highly turbulent wind field. The relatively low-resolution WRF model cannot detect such small-scale features. Furthermore, the SAR wind retrieval algorithm can resolve spatial inhomogeneity in the wind field, which, in this case, may result from the variable topography. In addition, the SAR wind fields can resolve finer coastal, topographic, and turbulent structures.
The linear regression analysis of the wind direction deduced from SAR using 2D FFT and the QuikSCAT wind direction shows a negative bias of $2.18^{\circ}$, and a RMS of $19.3^{\circ}$. This is better than the linear regression comparing SAR-retrieved wind direction and WRF wind direction $\left(2.73^{\circ}\right.$ bias and $\left.34.20^{\circ} \mathrm{RMS}\right)$. These results are based on case-by-case comparisons. Previous comparisons between SAR and QuikSCAT by Monaldo et al. (2004) were limited to comparisons of wind speed. A study by Horstmann and Koch (2005) showed that a comparison of wind direction from SAR using the 2D FFT with the German Weather Service (DWD) model resulted in a bias of $-5.18^{\circ}$ and RMS of $39.1^{\circ}$. These are higher than the results presented in this paper. In their research, scalloping caused the appearance of linear features aligned in a particular direction, within the scales evaluated by the 2D FFT method. This lead to a misinterpretation of FFT-derived wind direction. Our study area has a subtropical monsoon climate, where the homogeneous distribution of wind can be captured effectively by SAR images. Therefore, the 2D FFT method is well suited to wind direction retrieval in the ECS. In our study, the case-by-case comparisons of SAR wind direction with QuikSCAT products and WRF results show high $R^{2}$ values of 0.95 and 0.82 , respectively. Thus, wind direction retrieval using the $2 \mathrm{D}$ FFT method is reliable. A linear regression analysis of SAR-retrieved and QuikSCAT wind speeds exhibits a bias of $0.16 \mathrm{~m} / \mathrm{s}$ and RMS of $1.04 \mathrm{~m} / \mathrm{s}$. These are slightly better than those for wind speeds deduced from SAR and from the WRF model $(0.27 \mathrm{~m} / \mathrm{s}$ bias and $1.60 \mathrm{~m} / \mathrm{s} \mathrm{RMS})$. In this study, the correlation between QuikSCAT and SAR-retrieved wind speeds is 0.92 , which is very close to the $R^{2}$ value of 0.93 that Monaldo et al. reported (2004).

Our comparisons indicate that the SAR-retrieved data correspond more closely to QuikSCAT than WRF data, possibly because SAR and QuikSCAT have a similar scattering mechanism and theoretical background. Furthermore, the high-resolution SAR images can capture smaller scale wind fields over the ocean surface and investigate their spatial variation. The WRF model does not have this ability, particularly in coastal areas. Our promising results indicate that wind direction retrieval using the 2D FFT method and wind speed retrieval using the CMOD4 model are reliable and applicable. However, using the 2D FFT method to determine wind direction from SAR streaks is slightly subjective, because direction vectors unrelated to wind have to be separated from these 

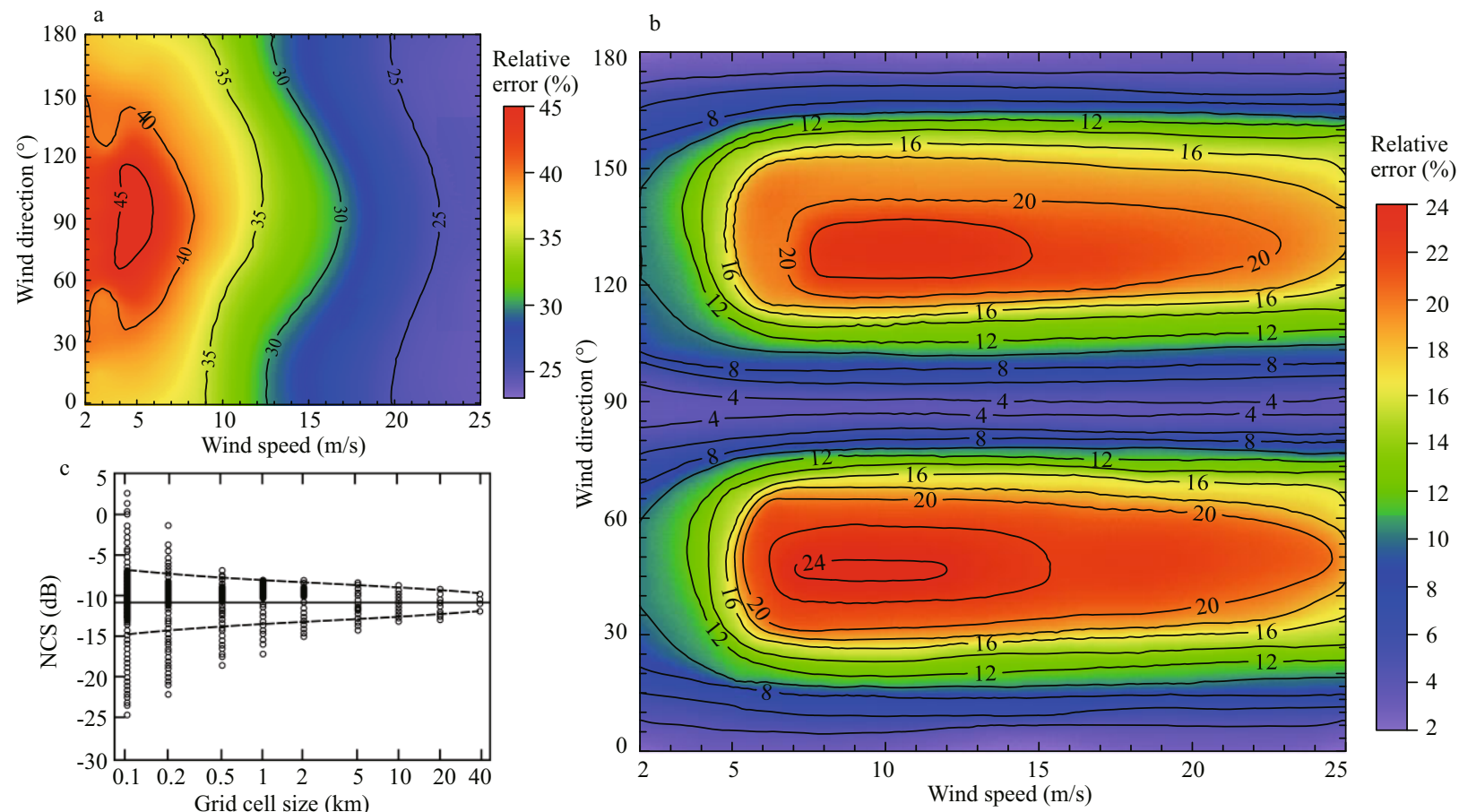

Fig.5 Estimated relative error as a percentage of wind speed due to (a) an inaccuracy of $\pm 0.5 \mathrm{~dB}$ in NRCS, (b) an uncertainty of $\pm 10^{\circ}$ in wind direction for an incidence angle of $23^{\circ}$, and (c) the effect of grid cell size on NRCS

linear features. In addition, the $180^{\circ}$ ambiguity in wind direction is an important issue, which can only be resolved by the SAR image itself if wind shadowing is visible in the lee of coastlines. If such features are not present, other ancillary data have to be taken into account (e.g., in-situ measurements or numerical models). Obtaining an accurate initial wind direction to input into CMOD4 is the key challenge in SAR wind speed retrieval. Moreover, CMOD4 underestimates high wind speeds ( $>20 \mathrm{~m} / \mathrm{s})$, according to the comparison between SAR wind speed and WRF output (Fig.4d). Donnelly et al. (1999) and Katsaros et al. (2002) also demonstrated this limitation. CMOD5 was specifically designed to derive high wind speeds and has presented encouraging results (Horstmann et al., 2005), which could allow complete wind field retrieval from SAR images under different atmospheric conditions.

Therefore, a combination of the 2D FFT for wind direction and the CMOD4 algorithm for wind speed is a promising method of retrieving valuable wind field information from SAR images operating in the $\mathrm{C}$-band with VV polarization. The large spatial coverage and high resolution of SAR, together with its all-weather capability, make it irreplaceable in the extraction of detailed wind field information, especially in coastal regions.

\subsection{Error estimation of CMOD4 wind speed}

When computing wind speed using SAR images and the CMOD4 function, the accuracy relies heavily on the input parameters such as NRCS, wind direction, and incidence angle. The error related to the incidence angle can be assumed to be negligible, because it can be accurately calculated from SAR images. Other major sources of error are speckle, data processing, and atmospheric conditions.

The error resulting from NRCS is largely dependent on the sensor and its calibration. Small calibration offsets can cause significant changes in wind speed retrieval (Horstmann et al., 2000a). Although we have accurately calibrated the SAR images, this error still exists. The NRCS measured by ERS-2 SAR is typically in the range of $\pm 0.5 \mathrm{~dB}$ (Laur et al., 2004). To quantitatively evaluate the error caused by calibration accuracy, we calculated the relative error in wind speed assuming an accuracy of $\pm 0.5 \mathrm{~dB}$ (Fig.5a). The computations used CMOD4 with an incidence angle of $23^{\circ}$, wind speeds of $2-25 \mathrm{~m} / \mathrm{s}$, and wind directions between $0^{\circ}$ (upwind) and $180^{\circ}$ (downwind) clockwise from the radar look direction. The maximum relative error $(45 \%)$ occurred at wind speeds of $4-6 \mathrm{~m} / \mathrm{s}$ and wind directions $60^{\circ}-120^{\circ}$ from the antenna direction. The relative error decreased 
considerably as wind speed increased, and was slightly lower for the upwind and downwind directions than for crosswind directions. In addition, ERS-2 SAR products give radiometric resolutions of $2.07 \mathrm{~dB}$ (Meadows et al., 2000). These inaccuracies of NRCS result in large wind speed errors, especially for strong winds and small incidence angles.

Obtaining an accurate initial wind direction is a crucial challenge in SAR wind speed retrieval. We have quantified the errors introduced by SAR wind speed retrieval by calculating the relative error assuming a $10^{\circ}$ error in wind direction (Fig.5b). We performed the computations using the same model and ranges of input parameters as in the evaluation of error caused by calibration accuracy. The relative error was maximized $(24 \%)$ at wind speeds of $7-12 \mathrm{~m} / \mathrm{s}$ and wind directions around $45^{\circ}$ from the flight direction. Another smaller maximum error occurred when the wind direction was near $135^{\circ}$. Due to the symmetry of the hybrid model function, the maximum relative error also occurred near $225^{\circ}$ and $315^{\circ}$. The relative error was smallest when the wind blows toward, away from, or orthogonal to the radar. It peaked when the wind direction was approximately $45^{\circ}$ and $135^{\circ}$ from the flight direction.

The granular appearance of SAR images is the result of speckle, which originates from the random scattering of objects within elementary resolution cells. We have calculated the effect of grid cell size on NRCS using an ERS-2 SAR image from 02:27 UTC, May 4, 2006. The calibration procedure considered the power loss caused by analog to digital converter (ADC) saturation and replica power variations. Then, we averaged the NRCS (in decibels) over the areas. We repeated the procedure using increasingly smaller areas, down to a grid size of $100 \mathrm{~m} \times 100 \mathrm{~m}$. The resulting NRCS values were calculated using the corresponding grid cell size (Fig.5c). The mean values of each area were almost constant at $-10.88 \mathrm{~dB}$. When the grid cell size was greater than $1.0 \mathrm{~km}$, there were no significant effects on NRCS values. However, when it was less than $0.5 \mathrm{~km}$, the speckle had a large effect on the variance of NRCS, so the results should not be interpreted as wind variation. In addition, point targets such as ships and oil platforms often result in high backscatter values that strongly influence the mean NRCS, leading to high wind speeds. Therefore, it is often necessary to apply a spatial filter to SAR images, especially when they are being used for advanced vision tasks such as the retrieval of ocean surface parameters (Argenti and Alparone, 2002).
Resonant Bragg scattering dominates the radar backscatter of the ocean surface for grid cell sizes above $0.5 \mathrm{~km}$. It is strongly influenced by local wind fields.

There are other sources of error in wind speed retrieval using SAR. Atmospheric stability at the acquisition time of each image often affects wind speed retrieval (Christiansen et al., 2006). Generally, wind speed derived from SAR under stable conditions underestimates the observed $10 \mathrm{~m}$ wind, whereas unstable conditions result in overestimated values. In addition, ocean surface waves, internal boundary layers, and lee waves modulate SAR wind features, and have a negative effect on the accuracy of SAR wind retrieval (Lin et al., 2008). Therefore, image processing is an important step in SAR wind retrieval because it suppresses undesired information without losing the effective signal. Inappropriate image processing will result in large errors.

\subsection{Application of SAR-retrieved wind in numerical simulations}

Many physical oceanography researchers have focused on the expansion of the CDW. Wind forcing over the ECS is a critical factor in low-salinity water detachment from the CDW (Zhu et al., 1997; Moon et al., 2010). According to field observations carried out by the East China Normal University from July $2-9$, 2011, a saltwater tongue and a freshwater plume exist in the region. The saltwater tongue disperses off the Changjiang estuary, travelling from north to south at a depth of $5 \mathrm{~m}$. A freshwater plume acts as a counterpart, floating on a salty wedge close to the shore and flowing from south to north (Fig.6a). This salinity distribution has not been recorded in previous observations. We have used a 3D ocean circulation model to reveal the dynamic mechanism. We used the semi-implicit Estuarine, Coastal and Ocean Model (ECOM-si; Wu and Zhu, 2010) to simulate the salinity distribution, which considers the effects of Changjiang runoff, tides and tidal current, shelf circulation, and wind stress. We ran the model from June 1-July 9, 2011. We validated this model using in-situ data collected from the Changjiang estuary on July $2-9$, 2011. We used two sets of sea surface wind as inputs: WRF with a spatial resolution of $0.5^{\circ} \times 0.5^{\circ}$ and temporal resolution of $4 \mathrm{~h}$, and a compound dataset combining SAR-retrieval data at 02:01 UTC on July 6, 2011 and WRF estimations.

The simulation results reproduce the saltwater tongue and freshwater plume observed in the field 

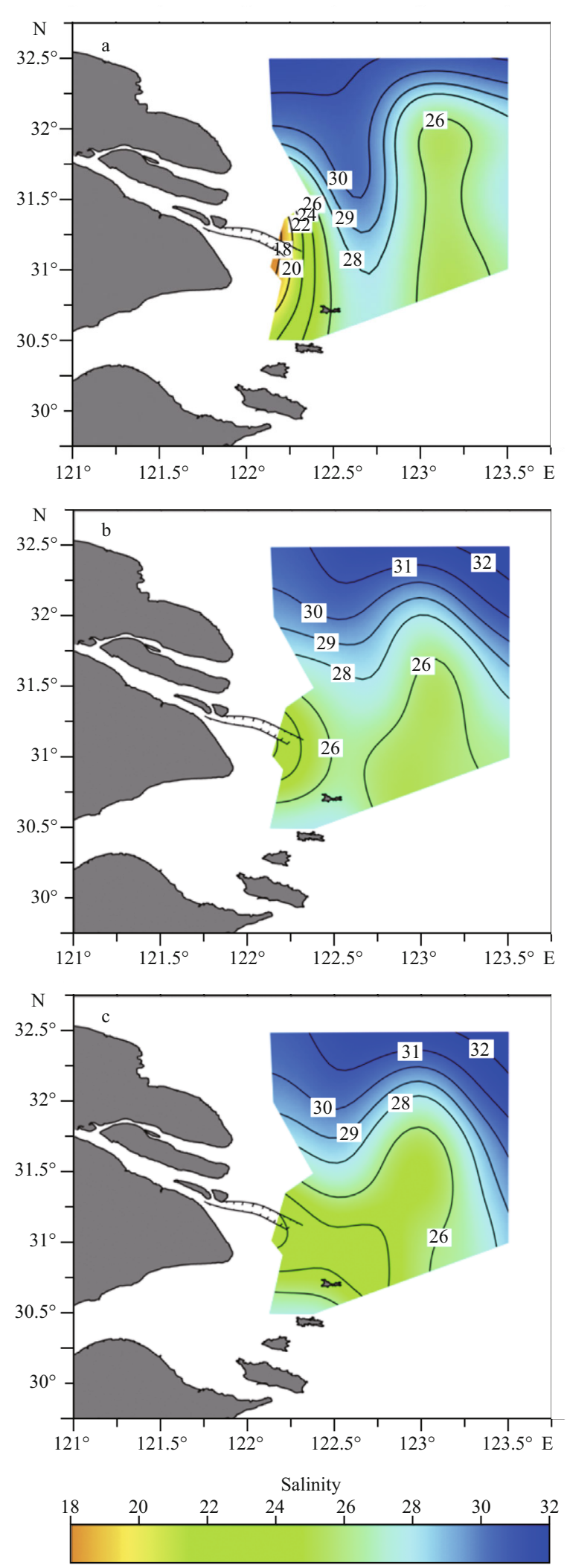

Fig.6 Salinity distribution off the Changjiang estuary at a depth of $5 \mathrm{~m}$ during the period July 2-9, 2011

a. field observations; $b$. wind parameters from a compound dataset combining SAR-retrieved and WRF estimations as inputs to ECOM-si; c. wind parameters from WRF as inputs to ECOM-si. measurements (Fig.6b and c). However, the simulated salinity distribution characteristics are not as apparent in either dataset as in the field observations, probably because of tidal mixing in the vertical direction ( $\mathrm{Wu}$ et al., 2011; Rung and Li, 2012). The salinity distributions based on the two sets of sea surface wind data are similar, although the SAR-compound dataset results agree slightly more with the field observations. This is because the wind speed $(4-6 \mathrm{~m} / \mathrm{s})$ retrieved from SAR on July 6 is higher than that from WRF (3-6 m/s). SAR can also reveal high-resolution coastal wind fields, which leads to a relatively perfect simulation of the salinity distribution when using the compound dataset. On the other hand, SAR has a long revisit period so only one SAR image is available for the compound dataset. We believe that, if a new generation of earth observation satellites carrying SAR sensors are launched in the future; several SAR images covering the same area will be available for a single day. This could satisfy the need for increased temporal resolution of ocean surface wind information when applying numerical ocean models, which would considerably enhance the accuracy of numerical simulations.

\section{CONCLUSION}

SAR can measure sea surface wind fields at sub$\mathrm{km}$ scales. Our investigation highlights the effectiveness of 2D FFT algorithms for wind direction retrieval and SCAT-based models for wind speed retrieval, using SAR images with VV polarization. SCAT-based methods have already been applied in a quasi-operational environment (Monaldo, 2000). Therefore, we believe that SAR can provide a powerful complement to conventional wind measurement techniques, because of its high resolution. Furthermore, because the SAR wind retrieval technique is based on an imaging process, it provides a useful diagnostic tool for other techniques and detects small-scale wind structures that could allow quantitative estimations of atmospheric stability (Sikora et al., 1995; Young et al., 2005). Wind field data retrieved from SAR images in coastal areas are very valuable for offshore wind resource assessment, as they can provide sufficient and accurate spatial information in the early stages of wind farm planning.

We have also estimated different sources of error during wind speed retrieval. We quantitatively estimated the effect of inaccuracies in NRCS, uncertainties of wind direction, and speckle with respect to ERS-2 SAR. The relative error caused by 
inaccuracies in NRCS decreases significantly with increasing wind speed. The highest errors caused by uncertainties of wind direction occur approximately $45^{\circ}, 135^{\circ}, 225^{\circ}$, and $315^{\circ}$ from the radar look direction. Speckle begins to influence the retrieved wind variation when the grid cell size is below $0.5 \mathrm{~km}$. We introduced SAR-retrieved wind fields into numerical simulations of the salinity distribution off the Changjiang estuary. The results were of sufficient quality.

Future investigations should concentrate on fully exploiting SAR data to improve the retrieval accuracy of high resolution wind, especially for high wind speeds and polarization. Topographical effects must be carefully examined when wind vectors are estimated for sites close to shorelines. In addition, focus should be placed on the synergetic use of multiple sensors. Operational observation systems should integrate radar data and optical satellite images to analyze different marine parameters, such as surface waves, oceanic circulation, ocean variability, and the transport of suspended matter. Although much remains to be investigated, our encouraging results suggest that further efforts to combine SAR data with other meteorological observations and numerical model outputs could eventually yield operational high-resolution wind field products. Furthermore, our numerical simulation results suggest the temporal resolution of SAR images must be increased to significantly improve the accuracy of simulation results, which may be feasible in the near future.

\section{ACKNOWLEDGMENT}

We would like to thank the European Space Agency (ESA) for providing SAR data via the support of the ESA-approved Dragon 3 (ID 10593). We are grateful to the anonymous reviewers for their helpful comments and suggestions.

\section{References}

Argenti F, Alparone L. 2002. Speckle removal from SAR images in the undecimated wavelet domain. IEEE Trans. Geosci. Remote Sens., 40(11): 2 363-2 374.

Attema E P W. 1991. The Active Microwave Instrument onboard the ERS-1 satellite. Proceedings of the IEEE, 79(6): 791-799, http://dx.doi.org/10.1109/5.90158.

Blanton J, Wenner E, Werner F, Knott D. 1995. Effects of wind-generated coastal currents on the transport of blue crab megalopae on a shallow continental shelf. Bull. Mar. Sci., 57(3): 739-752.

Chang P H, Isobe A. 2003. A numerical study on the Changjiang diluted water in the Yellow and East China Seas. J.
Geophys. Res-Oceans, 108(C9): 1-17, http://dx.doi.org/ 10.1029/2002JC001749.

Christiansen M B, Koch W, Horstmann J, Hasager C B, Nielsen M. 2006. Wind resource assessment from C-band SAR. Remote Sens. Environ., 105(1): 68-81.

Dankert H, Horstmann J, Rosenthal W. 2003. Ocean wind fields retrieved from radar-image sequences. J. Geophys. Res-Oceans, 108(C11): 2 150-2 152, http://dx.doi.org/10. 1029/2003JC002056.

Done J, Davis C A, Weisman M. 2004. The next generation of N W P: explicit forecasts of convection using the weather research and forecasting (WRF) model. Atmos. Sci. Lett., 5(6): 110-117, http://dx.doi.org/10.1002/asl.72.

Donnelly W, Carswell R M, Chang P, Wilkerson J. 1999. Revised ocean backscatter models at $\mathrm{C}$ and $\mathrm{Ku}$ band under high wind conditions. J. Geophys. Res-Oceans, 104(C5): 11 485-11 497, http://dx.doi.org/10.1029/1998JC 900030 .

Elfouhaily T, Thompson D R, Vandemark D, Chapron B. 1999. A new bistatic model for electromagnetic scattering from perfectly conducting random surfaces. Waves in Random Media, 9(3): 281-294.

Fetterer F, Gineris D, Wackerman C C. 1998. Validating a scatterometer wind algorithm for ERS-1 SAR. IEEE Trans. Geosci. Remote Sens., 36(2): 479-492.

Fichaux N, Ranchin T. 2002. Combined extraction of high spatial resolution wind speed and wind direction from SAR images: a new approach using wavelet transform. Can. J. Remote Sens., 28(3): 510-516.

Freilich M H, Chelton D B. 1986. Wavenumber spectra of pacific winds measured by the Seasat scatterometer. $J$. Phys. Oceanogr., 16(4): 741-757.

Garratt J R. 1990. The internal boundary layer-a review. Boundary-Layer Meteorology, 50(1-4): 171-203.

Genovese S J, Witman J D. 2004. Wind-mediated diel variation in flow speed in a Jamaican back reef environment: Effects on ecological processes. Bull. Mar. Sci., 75(2): 281-293.

Gerling T W. 1986. Structure of the surface wind field from the Seasat SAR. J. Geophys. Res-Oceans, 91(C2): 2 3082 320, http://dx.doi.org/10.1029/JC091iC02p02308.

Haarpaintner J. 1999. The Storfjorden polynya: ERS-2 SAR observations and overview. Polar Research, 18(8): 175182, http://dx.doi.org/10.1111/j.1751-8369.1999.tb00290.x.

Hasager C B, Nielsen M, Astrup P, Barthelmie R, Dellwik E, Jensen N O, Jørgensen B H, Pryor S C, Rathmann O, Furevik B R. 2005. Offshore wind resource estimation from satellite SAR wind field maps. Wind Energy, 8(4): 403-419.

Horstmann J, Koch W, Lehner S, Tonboe R. 2000a. Mapping of mesoscale wind field using RADARSAT-1 ScanSAR images. IEEE Conference and Exhibition Oceans 2000MTS, 2: 1 321-1 327, http://dx.doi.org/10.1109/ OCEANS.2000.881787.

Horstmann J, Koch W, Lehner S, Tonboe R. 2000b. Wind retrieval over the ocean using synthetic aperture radar with C-band $\mathrm{HH}$ polarization. IEEE Trans. Geosci. Remote Sens., 38(5): 2 122-2 131.

Horstmann J, Koch W, Lehner S, Tonboe R. 2002. Ocean 
winds from RADARSAT-1 ScanSAR. Can. J. Remote Sens., 28(3): 524-533.

Horstmann J, Koch W, Lehner S. 2004. Ocean wind field retrieved from the advanced synthetic aperture radar aboard ENVISAT. Ocean Dyn., 54(6): 570-576.

Horstmann J, Koch W. 2005. Measurement of ocean surface winds using synthetic aperture radars. IEEE J. Ocean Eng., 30(3): 508-515.

Horstmann J, Thompson D R, Monaldo F, Iris S, Graber H C. 2005. Can synthetic aperture radars be used to estimate hurricane force winds. Geophys. Res. Lett., 32(22): 1-5, http://dx.doi.org/10.1029/2005GL023992.

Johannessen J A. 2000. Coastal observing systems: the role of synthetic aperture radar. Johns Hopkins APL Technical Digest, 21: 7-14.

Katsaros K, Vachon P, Lio W, Black P. 2002. Microwave remote sensing of tropical cyclones from space. $J$. Oceanogr., 58: 137-151.

Kerbaol V, Chapron B, Vachon P W. 1998. Analysis of ERS$1 / 2$ synthetic aperture radar wave mode imagettes. $J$. Geophys. Res-Oceans, 103(C4): 7 833-7 846, http://dx. doi.org/10.1029/97JC01579.

Kim D J, Moon W M. 2002. Estimation of sea surface wind vector using RADARSAT data. Remote Sens. Environ., 80(1): 55-64.

Koch W. 2004. Directional analysis of SAR images aiming at wind direction. IEEE Trans. Geosci. Remote Sens., 42(4): 702-710.

Korsbakken E, Johannessen J A, Johannessen O M. 1998. Coastal wind field retrievals from ERS synthetic aperture radar images. J. Geophys. Res-Oceans, 103(C4): $7857-$ 7 874, http://dx.doi.org/10.1029/97JC02580.

Laur H, Bally P, Meadows P, Sanchez J, Schaettler B, Lopinto E, Esteban D. 2004. Derivation of the Backscattering Coefficient in ESA ERS SAR PRI Products. European Space Agency, Frascati.

Lehner S, Schulz-Stellenfleth J, Schattler B, Breit H, Horstmann J. 2000. Wind and wave measurements using complex ERS-2 SAR wave mode data. IEEE Trans. Geosci. Remote Sens., 38(5): 2 246-2 257.

Lin $\mathrm{H}, \mathrm{Xu}$ Q, Zheng Q. 2008. An overview on SAR measurements of sea surface wind. Progress in Natural Science, 18(8): 913-919.

Meadows P J, Rosich B, Fernandez D E. 2000. The performance of the ERS-2 Synthetic Aperture Radar. In Proc. of the ERSENVISAT Symposium. Goteborg, Sweden.

Monaldo F M, Thompson D R, Pichel W G, Clemente-Colon P. 2004. A systematic comparison of QuikSCAT and SAR ocean surface wind speeds. IEEE Trans. Geosci. Remote Sens., 42(2): 283-291.

Monaldo F M. 2000. The Alaska SAR demonstration and nearreal-time synthetic aperture radar winds. Johns Hopkins APL Technical Digest, 21: 75-84.

Moon J, Hirose N, Yoon J, Pang I. 2010. Offshore detachment process of the low-Salinity water around Changjiang bank in the East China Sea. J. Phys. Oceanogr., 5(40): 1035 1053.
Rung Z, Li M. 2012. Tidal effects on the bulge region of Changjiang River plume. Estuar. Coast. Shelf Sci., 97: 149-160.

Sikora T D, Young G S, Beal R C, Edson J B. 1995. Use of spaceborne synthetic aperture radar imagery of the sea surface in detecting the presence and structure of the convective marine atmospheric boundary layer. Mon. Wea. Rev., 123(12): 3 623-3 632.

Stoffelen A, Anderson D. 1997. Scatterometer data interpretation: estimation and validation of the transfer function CMOD4. J. Geophys. Res., 102(C3): $5767-$ 5 780, http://dx.doi.org/10.1029/96JC02860.

Stull R B. 1988. An Introduction to Boundary Layer Meteorology. Kluwer Academic Publishers, New York.

Thompson D R, Elfouhaily T M, Chapron B. 1999. Polarization ratio for microwave backscattering from the ocean surface at low to moderate incidence angles. IEEE International Geosci. Remote Sens. Symposium Proceedings, 3: 1 6711673.

Vachon P W, Dobson F W. 1996. Validation of wind vector retrieval from ERS-1 SAR images over the ocean. The Global Atmosphere and Ocean System, 5(2): 177-187.

Valenzuela G R. 1978. Theories for the interaction of electromagnetic and oceanic waves-a review. BoundLayer Meteorol., 13(1-4): 61-85, http://dx.doi. org/10.1007/BF00913863.

Wackerman C C, Rufenach C L, Shuchman R A, Johannessen J A, Davidson K L. 1996. Wind vector retrieval using ERS-1 synthetic aperture radar imagery. IEEE Trans. Geosci. Remote Sens., 34(6): 1 343-1 352.

Wright J. 1966. Backscattering from capillary waves with application to sea clutter. IEEE Trans. Antennas Propag., 14(6): 749-754.

Wu H, Zhu J R, Shen J, Wang H. 2011. Tidal modulation on the Changiiang River plume in summer. J. Geophys. ResOceans, 116: C08017, http://dx.doi.org/10.1029/ 2011JC007209.

Wu H, Zhu J R. 2010. Advection scheme with 3rd high-order spatial interpolation at the middle temporal level and its application to saltwater intrusion in the Changjiang estuary. Ocean Model., 33(1-2): 33-51.

Young G S, Sikora T N, Winstead N S. 2005. Use of synthetic aperture radar in finescale surface analysis of synopticscale fronts at sea. Wea. Forecasting, 20(3): 311-327, http://dx.doi.org/10.1175/WAF853.1.

Zhu J R, Li Y P, Shen H T. 1997. Numerical simulation of the wind field's impact on the expansion of the Changjiang River diluted water in summer. Oceanol. Limnol. Sin., 28(1): 72-79. (in Chinese with English abstract)

Zink M, Torres R, Buck C H, Rosich B, Closa J. 2002. The advanced SAR system on ENVISAT: mission status. Proceedings 4th European Conference on Synthetic Aperture Radar. p.175.

Zou Q, He Y, Perrie W, Vachon P W. 2007. Wind-vector estimation for RADARSAT-1 SAR images: validation of wind-direction estimates based upon geometry diversity. IEEE Trans. Geosci. Remote Sens. Lett., 4(1): 176-180. 